\title{
Wide-field angiography in retinal vein occlusions
}

\author{
Colin S. $\operatorname{Tan}^{1,2,3,4^{*}}$ (D) Kelvin Z. Li ${ }^{1}$ and SriniVas R. Sadda ${ }^{5}$
}

\begin{abstract}
Background: Retinal vein occlusion (RVO) is the second most common retinal vascular disease after diabetic retinopathy. It can result in significant visual loss from complications like macula edema, retinal and iris neovascularization, and vitreous hemorrhage. Recently, ultra-widefield imaging (UWF) has been developed for posterior pole visualization and has shown to be useful in the evaluation and treatment of RVO.

Main text: Ultra-widefield imaging (UWF) imaging allows for visualization of the retina up to an angle of $200^{\circ}$. This is especially important in detecting peripheral retinal pathologies, especially in retinal conditions such as RVO, where the disease process affects the peripheral as well as central retina. In particular, retinal non-perfusion in RVO is a risk factor for neovascularization. Various techniques, such as ischemic index and stereographic projection, have been described to assess areas of ischemia on UWF images. Retinal non-perfusion has an impact on disease complications, such as macular edema, and retinal and iris neovascularization. Retinal non-perfusion also has implications on disease response, including visual acuity, reduction in retinal edema and treatment burden.
\end{abstract}

Conclusion: Ultra-widefield imaging (UWF) imaging plays an important role in the assessment and management of $\mathrm{RVO}$, especially in measuring retinal non-perfusion in the peripheries.

Keywords: Retinal vein occlusion, Ultrawidefield imaging, Fluorescein angiography, Ischemic index, Macular edema

\section{Background}

Retinal vein occlusion (RVO) is the second most common type of retinal vascular disease, after diabetic retinopathy [1]. A meta-analysis of 15 studies from the United States, Europe, Asia and Australia reported a prevalence of 4.42 per 1000 for central RVO (CRVO) and 0.8 per 1000 for branch RVO (BRVO) [2]. The Beaver Dam Eye Study reported a prevalence of $0.6 \%$ for BRVO, and $0.1 \%$ for CRVO [3]. The prevalence of RVO increases with age. In the Beaver Dam Eye Study, persons aged 75 years or older were 6.7 times more likely to have BRVO compared to those aged between 43 and 54 years [3].

Major risk factors for RVO include hypertension [2, 4, 5], arteriosclerosis, hyper-triglyceridemia [4] and glaucoma $[2,6]$. In young patients, however, CRVO is more commonly associated with hematological abnormalities

\footnotetext{
*Correspondence: colintan_eye@yahoo.com.sg

1 National Healthcare Group Eye Institute, Tan Tock Seng Hospital, Jalan

Tan Tock Seng, 11, Singapore 308433, Singapore

Full list of author information is available at the end of the article
}

or pro-coagulant conditions, such as anemia, polycythemia, leukemia, multiple myeloma, abnormal platelet function and reduced anti-thrombin III [7].

RVO may result in significant visual loss. In the Central Vein Occlusion Study (CVOS) [8], visual outcomes varied according to baseline visual acuity (VA). Among those with good initial VA (defined as VA 20/40 or better), $65 \%$ maintained VA in the same range for the duration of the study. Patients with intermediate VA at baseline (20/50 to $20 / 200$ ) had variable outcomes, with $19 \%$ showing improvement in VA, $44 \%$ remaining in the same range, and $37 \%$ worsening by the end of the study. In contrast, those with poor VA at baseline (worse than 20/200) had an $80 \%$ chance of remaining worse than $20 / 200$.

\section{Pathophysiology of RVO}

Patients with RVO may experience visual loss from macular edema or vitreous hemorrhage and the complications related to this.

RVO is believed to result from compression of the retinal vein by the corresponding retinal arteriole, which is

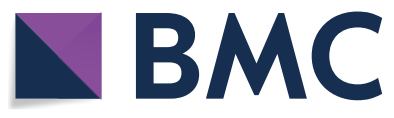

(c) The Author(s) 2019. This article is distributed under the terms of the Creative Commons Attribution 4.0 International License (http://creativecommons.org/licenses/by/4.0/), which permits unrestricted use, distribution, and reproduction in any medium, provided you give appropriate credit to the original author(s) and the source, provide a link to the Creative Commons license, and indicate if changes were made. The Creative Commons Public Domain Dedication waiver (http://creativecommons.org/ publicdomain/zero/1.0/) applies to the data made available in this article, unless otherwise stated. 
stiffened as a result of underlying hypertension and arteriosclerosis. This, together with damage to the vessel wall, results in thrombus formation [9]. Vascular occlusion leads to an increase in intraluminal venous pressure, which subsequently results in capillary endothelial cell damage, retinal hemorrhages, and eventually capillary dropout [10]. Capillary dropout and hypoxia then cause inflammation and an up-regulation of pro-inflammatory cytokines, such as vascular endothelial growth factor (VEGF) [11].

Increased VEGF production causes local inflammation and increased vascular permeability, which results in macular edema [11]. Studies have shown that the levels of both stimulatory cytokines, such as VEGF, and inhibitory cytokines like pigment epithelium-derived factor (PEDF), are correlated with the severity of macular edema [12, 13].

Retinal ischemia resulting from RVO may result in neovascularization, either in the anterior segment or in the retina. Neovascularization of the iris or angles may progress to neovascular glaucoma, while retinal neovascularization may bleed, resulting in vitreous hemorrhage $[2,14]$.

\section{Importance of ultra-widefield imaging in retinal vein occlusion}

Imaging plays an increasingly important role in ophthalmology [15-22], particularly for retinal conditions. Historically, flash color fundus photographs were obtained using $35-\mathrm{mm}$ slides, which provided a $30^{\circ}$ field of view after pupil dilation. This field of view allowed visualization of approximately $5 \%$ of the total retinal area [23].

Subsequent advances in fundus cameras and the advent of digital fundus photography allowed larger single fields of view to be obtained, ranging from $45^{\circ}$ to $50^{\circ}$. The coverage of the retina was increased by steering the eye in different directions of gaze, and obtaining overlapping retinal photographs.

One common method that has been used in many clinical trials is the Early Treatment Diabetic Retinopathy Study (ETDRS) 7 standard field (7SF) [24]. Using this method, 7 overlapping stereographic photographs were taken and assessed. Together, these images covered a width of $75^{\circ}$ or approximately $30 \%$ of the entire retinal surface [25].

More recently, ultra-widefield (UWF) imaging has been developed for posterior pole visualization [26]. Using devices such as the Optos 200 Tx or Optos California, images covering an angle of $200^{\circ}$ can be obtained in a single image. This accounts for approximately $80 \%$ of the retinal surface [27]. By steering the eye in different directions of gaze, additional areas of the retina can be covered, and it is possible to visualize the ora serrata in cooperative patients [28].The steered images can also be montaged to obtain a single composite image. Ultrawidefield imaging has been used in color fundus photography [29], fundus autofluorescence [30-32], fluorescein angiography (FA) [21,33-35] and indocyanine green angiography [36].

UWF images have several advantages compared to conventional fundus photography. In particular, a large portion of the retina may be captured on a single image (Fig. 1), whereas conventional fundus photography requires multiple images and still covers a smaller area of the retina. Thus UWF imaging may avoid the need to montage images, where artefacts may occur at the borders of the overlapping images, or lesions which occur at the regions of overlap may be masked [37].

In addition, UWF images can be obtained without pupil dilation, thus minimizing inconvenience to the patient. Acquiring UWF images is also faster compared to conventional photography. In one study, the time taken to acquire nonmydriatic UWF images was significantly shorter compared to that of dilated fundus photography in the ETDRS 7 standard fields $(170 \pm 80$ vs. $370 \pm 130 \mathrm{~s}$, $\mathrm{p}<0.001)$ [29].

Images taken using the Optos device also have high resolution $(3900 \times 3072$ pixels, which allows 17 to 22 pixels per degree of view [38]. In addition, the Optos pseudocolor images are taken using different wavelengths, which allow visualization of the different layers of the retina using the red or green filters.

Studies have demonstrated the importance of detecting peripheral retinal pathology in various retinal conditions,

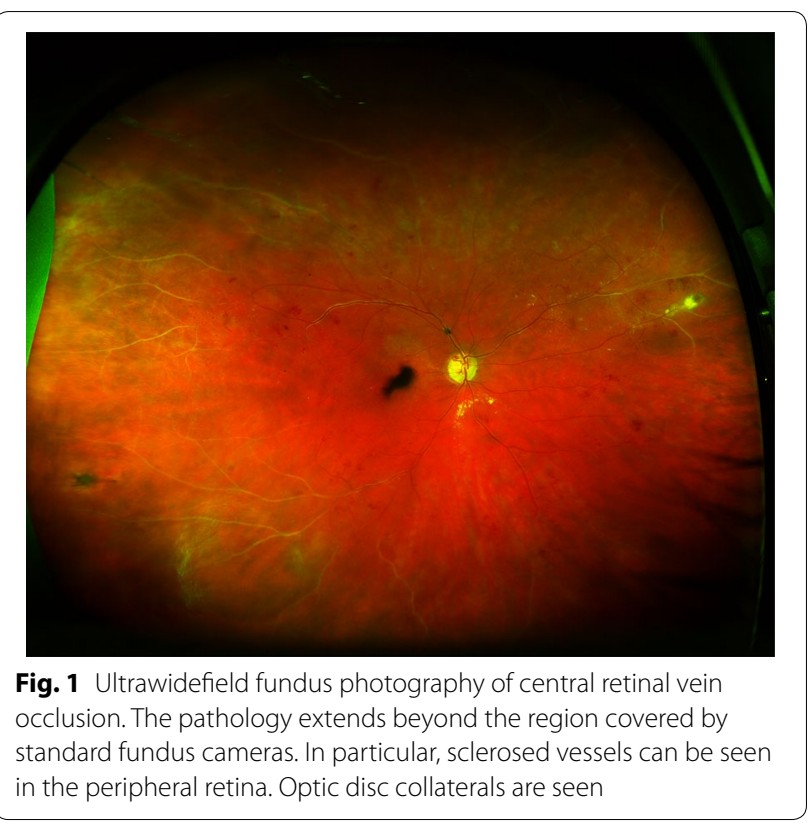


including RVO [33, 39], diabetic retinopathy [37, 40, 41] and age-related macular degeneration [30, 31]. For example, in diabetic retinopathy, lesions may be located more peripherally, predominantly outside the ETDRS 7SF, and would be missed using conventional imaging [25].

\section{Importance of widefield angiography in RVO}

The disease process in RVO affects the peripheral as well as central retina, and lesions may be located well beyond the posterior pole (Fig. 1). One of the sequelae of RVO is retinal non-perfusion, which is a risk factor for iris and retinal neovascularization [42, 43]. In addition, retinal non-perfusion is believed to be a source of VEGF drive, and the elevated VEGF levels may induce persistent macular edema [39].

\section{Assessing the extent of retinal non-perfusion}

In retinal imaging devices, the optics of a device in conjunction with the optics of the patient's eye will map the 3-dimensional retina to a 2-dimensional image. This mapping distorts the image in a similar way when creating a flat map of the earth. For widefield imaging devices, this distortion will be larger than for traditional fundus cameras. By using stereographic projection, which mathematically projects from a three-dimensional structure to a two-dimensional image, directionality from a central point is preserved. Furthermore, this projection is conformal; it preserves angles where curves meet, which ensures shapes are not distorted. This property ensures that angles can be measured anywhere on the image, which is crucial for image registration between devices. While this projection may portray the relative locations of structures more accurately, it does so at the cost of equilaterality and equidistance, i.e., area and distance will not be the same throughout the image [33]. Because of this, lesions in the periphery appear larger than if they are located more centrally. As illustrated in Fig. 2, two ellipses of equal size on the image (each comprising 110,288 pixels) have areas of $30.9 \mathrm{~mm}^{2}$ and $17.2 \mathrm{~mm}^{2}$ respectively.

After images are represented in a stereographic projection, we can make accurate area, distance and angle measurements as the mathematics is widely known. The methods for making these measurements on retinal images were incorporated into the DICOM standard as Supplement 173 [44].

To facilitate assessment of areas of ischemia on UWF images, a method known as the ischemic index was described [45]. The ischemic index is the ratio of the number of pixels in the areas of non-perfusion to the total number of pixels of the visible retina (Fig. 3). Using the ischemic index, the amount of retinal nonperfusion in RVO was shown to vary considerably.

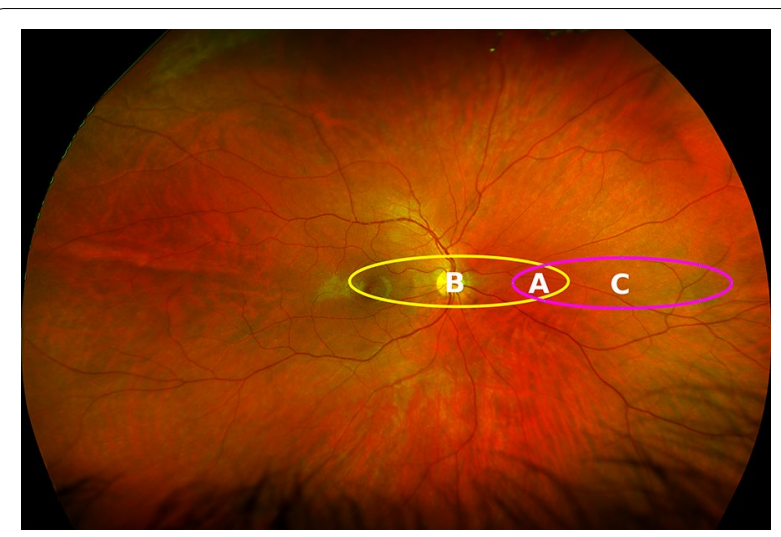

Fig. 2 Ultra-widefield image of a human retina in stereographic projection where both annotated ellipses comprise 110,288 pixels. The area shared by both ellipses $A$ is $3.59 \mathrm{~mm}^{2}$. The two ellipses labelled $B$ and $C$ have an area of $30.9 \mathrm{~mm}^{2}$ and $17.2 \mathrm{~mm}^{2}$ respectively (image courtesy of Jano Van Hemert)

Among patients with BRVO, the ischemic index varied from 0.1 to $61.3 \%[33,39,45]$. The range of retinal nonperfusion in CRVO was even greater, varying from 0 to $99 \%[33,39,45]$.

The use of the ischemic index, however, has significant limitations. As mentioned earlier, lesions which appear to be similar in size may differ in actual area, depending on the location of the lesion on the image. As a result, the size of peripheral lesions may be overestimated, especially since ophthalmologists typically use reference structures in the posterior pole, such as the optic disc, to estimate the size of other structures in the fundus. Another consideration is that the area of visible retina varies considerably between eyes [33] and between the same eye at separate time points. Since the ischemic index is based on the ratio of non-perfusion to visible retina, variability in the area of visible retina could potentially confound the comparison of the extent of ischemia, and whether this is changing over time. Regions of the retina may also be difficult to grade because of artefacts caused by eyelids or eye lashes, especially in the periphery, or by media opacity such as vitreous hemorrhages. It is also uncertain whether the ischemic index obtained using different widefield imaging devices are comparable.

These limitations have been addressed by the use of stereoscopic projection software [33, 46, 47], which compensates for the device-specific three-dimensional (retina) to two-dimensional (an image of the retina) projection. In stereographic projection images, the same angle is maintained at every eccentricity. This means that angular distances are constant, and facilitates accurate measurement between points at various eccentricities. The stereographic projection software is built into 

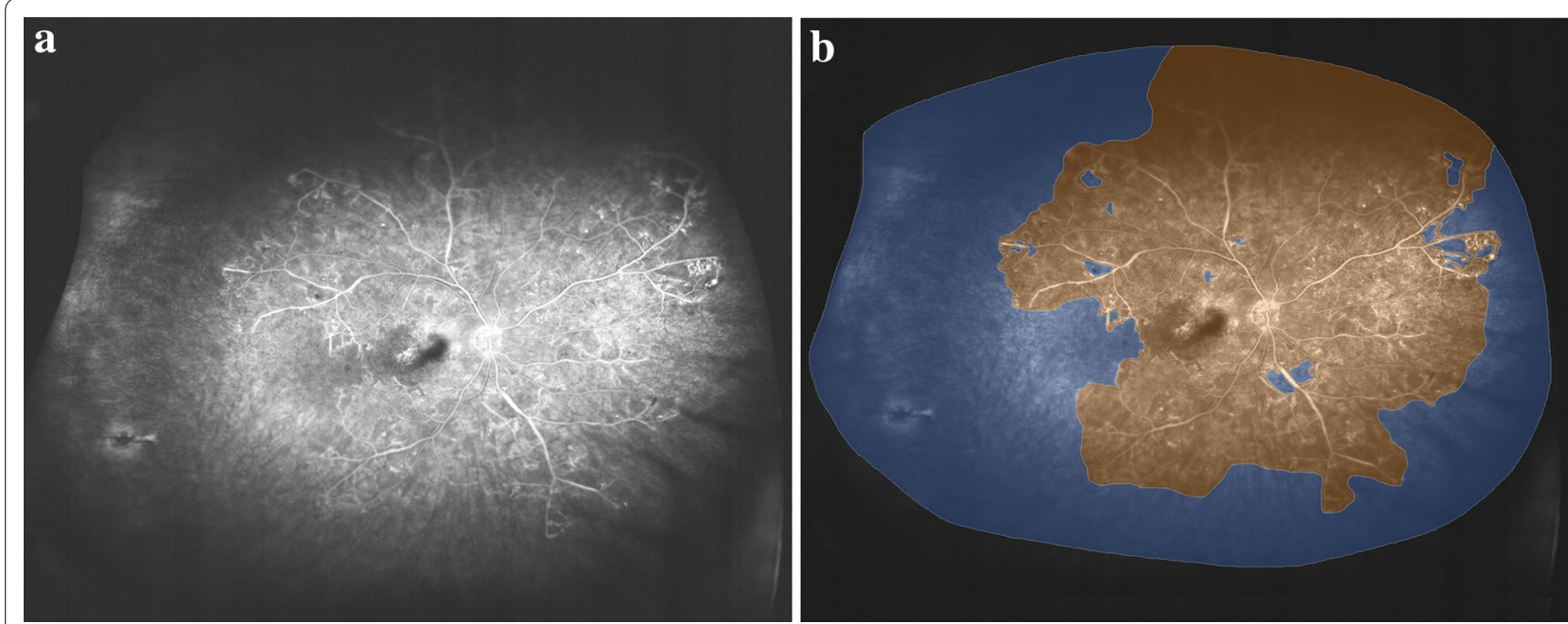

Fig. 3 Ischemic central retinal vein occlusion. a Ultrawidefield fluorescein angiogram showing extensive areas of capillary non-perfusion throughout the posterior pole. $\mathbf{b}$ Grading diagram illustrating the regions of perfusion (orange) and ischemia (blue)

the image capture software of the current Optos imaging devices, and allows accurate and precise measurement of areas and distances anywhere on the image.

Using stereographic projection, the area of nonperfusion in a cohort of RVO patients ranged from 0 to $365.4 \mathrm{~mm}^{2}$, with a mean of $95.1 \mathrm{~mm}^{2}$ and median of $49.6 \mathrm{~mm}^{2}$ [33]. This is equivalent to a mean of 36.7 disc areas and a median of 19.1 disc areas. The largest area of retinal non-perfusion $\left(365.4 \mathrm{~mm}^{2}\right)$ in this cohort is equivalent to 141 disc areas. Not surprisingly, the area of non-perfusion was larger in patients with CRVO (mean $135.8 \mathrm{~mm}^{2}$, range 5.3-365.4) compared to BRVO (mean $67.3 \mathrm{~mm}^{2}$, range $\left.0-224.3\right)(\mathrm{p}=0.045)$ [33]. In a study of 22 patients [48], peripheral non-perfusion was detected on widefield imaging even though 7 of these patients were initially classified as perfused using CVOS study criteria. The mean area of retinal non-perfusion was found to be $368.7 \mathrm{~mm}^{2}$.

It has been shown that the area of non-perfusion correlates well with the ischemic index $(\mathrm{R}=0.978, \mathrm{p}<0.001)$ [33]. However, measurement of areas of ischemia in anatomically correct units confers significant advantages, since these are units that ophthalmologists can relate to and understand more instinctively.

The total area of retina visible similarly has a wide range. In one cohort of patients with RVO, the total area of visible retina ranged from 559.4 to $797.7 \mathrm{~mm}^{2}$, with a mean of $690.6 \mathrm{~mm}^{2}$ [33]. In another study of the retinal vasculature which was conducted among normal subjects, the mean area of the normal perfused retina was $977.0 \mathrm{~mm}^{2}$. This was reported to vary with age, but not gender [49].
The area of retinal non-perfusion has been reported to change over time. In the Rubeosis anti-VEGF (RAVE) trial [50], all eyes demonstrated extensive areas of retinal non-perfusion. Patients experienced a mean loss of $8.1 \%$ of perfused retinal area per year, which is equivalent to 15 disc areas. The increase in retinal nonperfusion was $16.3 \%$ in the first year, $4.2 \%$ in the 2 nd year and $3.6 \%$ in the third year.

Recently, the accuracy of apparent changes in nonperfusion over time on UWF FA has been questioned. Gaudric and colleagues, noted that in some regions of apparent recovered perfusion following anti-VEGF therapy, companion optical coherence tomography (OCT) angiography of these same regions appeared to suggest persistent capillary drop-out (presented at the International Retinal Imaging Symposium, Feb 2018, Los Angeles, California). The explanation for the apparent discrepancy remains uncertain and is a topic of active investigation, but would suggest caution in the interpretation of regions of suspected re-perfusion on FA.

\section{Impact of retinal non-perfusion on disease manifestations}

Retina and iris neovascularization

The extent of retinal non-perfusion appears to correlate with the likelihood of neovascularization. In one study, the mean ischemic index among 15 eyes with neovascularization was $75 \%$ (range $47-100 \%$ ) whereas the eyes without neovascularization had a mean ischemic index of only $6 \%$ (range $0-43 \%$ ) [45]. Of note, all eyes that had neovascularization had an ischemic index greater 
than $45 \%$. The authors also found that the ischemic index had a significant correlation with presence of neovascularization.

\section{Relationship to macular edema}

Studies have suggested that the extent and location of retinal non-perfusion may be related to the presence of macular edema in RVO. It is believed that up-regulation of VEGF production from the regions of non-perfusion may contribute to the development and severity of macular edema.

Prasad et al. [51] reported that non-perfusion anterior to the equator was strongly associated with macular edema in retinal vein occlusion. In contrast, non-perfusion that was isolated to regions posterior to the equator were not significantly associated with macular edema.

In a study of 32 patients with CRVO or BRVO, the mean ischemic index was higher when macular edema was present compared to when the edema had resolved following treatment $(14.8 \%$ vs. $10.3 \%, \mathrm{p}<0.001)$ (Fig. 4$)$. When subdivided by CRVO (13 patients) and BRVO (19 patients), similar trends were observed (22.5\% when edema was present vs. $16.1 \%$ when edema had resolved for CRVO, $\mathrm{p}=0.003$; and $11.0 \%$ vs. $8.5 \%$ for $\mathrm{BRVO}$, $\mathrm{p}=0.003$ ) [39]. In this same study, patients with ischemic index $>10 \%$ had greater amount of retinal thickening compared to those with ischemic index $\leq 10 \%$ (central subfield thickness $520.8 \mu \mathrm{m}$ vs. $424.5 \mu \mathrm{m}, \mathrm{p}=0.029$ ).

In another study of 33 patients with BRVO, baseline central subfield thickness was $564 \mu \mathrm{m}$ among those with between 50 and 100 fields of peripheral retinal non-perfusion compared to $373 \mu \mathrm{m}$ among those with 0-49 fields of non-perfusion [52].

Investigators have suggested that the different regions of retinal ischemia may contribute to macula edema to different extents. In the WAVE study [53], which involved 24 patients with RVO, ischemic index was computed for the entire retina, as well for specific regions defined by a standardized grid: the perimacular area (PMA), near-peripheral area (NPA), midperipheral area (MPA) and far-peripheral area (FPA). All regions exhibited reduction in ischemic index compared to baseline. In this study, a significant correlation was found between central macular thickness and global ischemic index during follow-up $(r=0.22$, $p=0.03$ ). When different zones were analyzed, the PMA also showed a correlation with central macular thickness $(r=0.27, p=0.007)$. The change in ischemic index was also correlated with changes in central macular thickness in the total retina, PMA and NPA.

\section{Impact of retinal non-perfusion on treatment and follow up}

Visual acuity

The extent of retinal non-perfusion may correlate with the final visual acuity in RVO. In a study of 53 patients with BRVO, patients with greater retinal non-perfusion (50 to $>100$ fields) had final best-corrected visual acuity (BCVA) of 34.76 ETDRS letters, whereas those with smaller areas of retinal non-perfusion had BCVA of 40.63 letters [52].
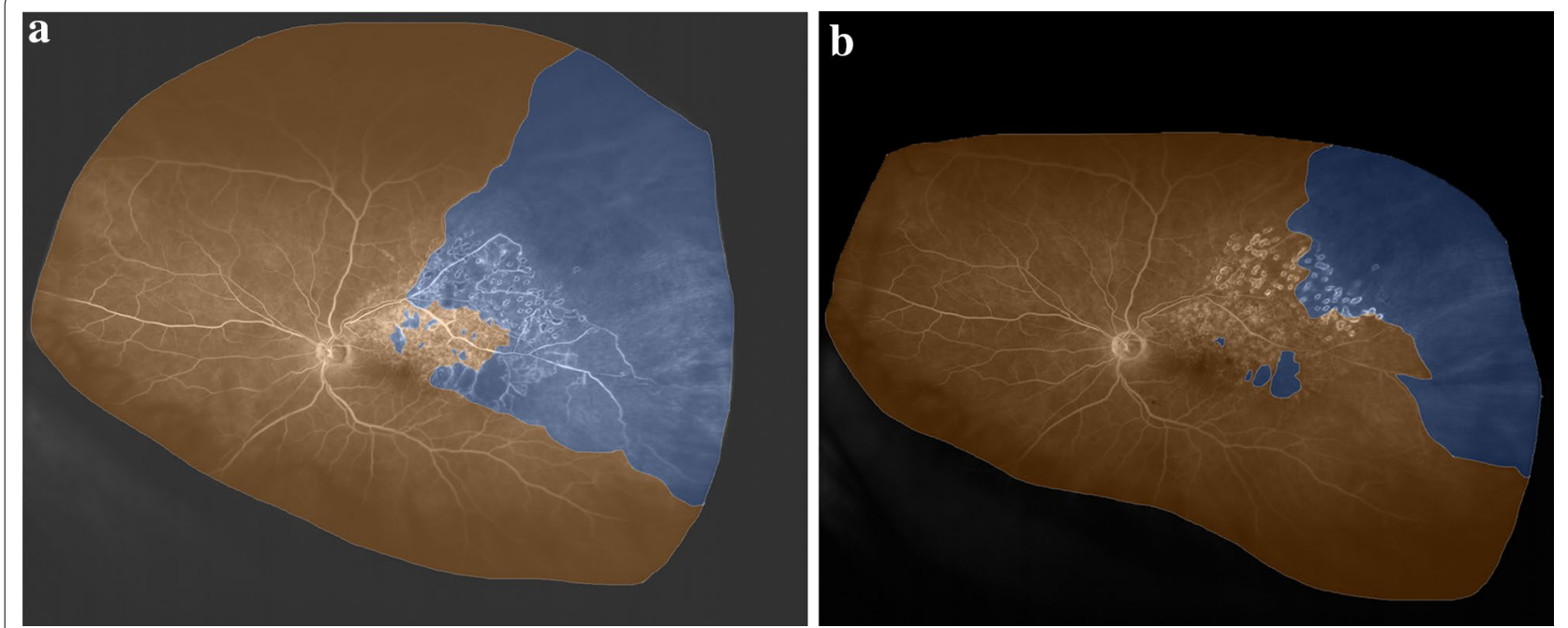

Fig. 4 Branch retinal vein occlusion. a Widefield fluorescein angiogram (FA) before treatment, showing a large area of non-perfusion superotemporally (blue). Regions of perfused retina are shaded orange. $\mathbf{b}$ Widefield FA performed after treatment. The area of retinal non-perfusion has reduced 
In a study of 32 patients with CRVO and BRVO, those with $>10 \%$ ischemic index at baseline experienced a significantly larger gain in BCVA compared to those with ischemic index $\leq 10 \%$ (12.4 vs. 0.9 letters, $p=0.036$ ) [39].

\section{Reduction in retinal edema}

Changes in retinal thickness has been shown to vary according to the extent of retinal perfusion. Among patients with ischemic index $>10 \%$, the mean decrease in OCT thickness was $296.1 \mu \mathrm{m}$ compared to $165.3 \mu \mathrm{m}$ for those with smaller areas of retinal non-perfusion [39]. A study of BRVO patients by Aghdam et al. [52] reported that central subfield thickness decreased by $222 \mu \mathrm{m}$ (from 564 to $342 \mu \mathrm{m}$ ) among those with 50 or more fields of non-perfusion compared to $79 \mu \mathrm{m}$ (from 373 to $294 \mu \mathrm{m}$ ) among those with less than 50 fields of non-perfusion.

\section{Number of anti-VEGF injections}

Some authors have reported that the number of antiVEGF injections varies with the extent of retinal non-perfusion. In a series of 54 patients with CRVO, patients with $<5$ disc areas of non-perfusion had a mean of 4 injections, compared to a mean of 9 for those with $>5$ disc areas [54].

In contrast, in a study of 32 patients with CRVO or $B R V O$, there were no significant differences in the number of anti-VEGF or dexamethasone implants administered between the groups with larger or smaller amounts of retinal non-perfusion [39].

\section{Targeted retinal photocoagulation}

The observations described above have led some ophthalmologists to suggest a role for targeted retinal photocoagulation (TRP), where retinal photocoagulation is applied selectively to areas of ischemia seen on widefield FA. Since it is believed that the areas of ischemia are the source of VEGF drive, selectively photocoagulating those areas should theoretically be sufficient to reduce the VEGF drive, and consequently have an impact on the extent macular edema. By extension, applying laser to regions of healthy or perfused retina would theoretically be unnecessary as these areas would not be expected to contribute significantly to VEGF levels in the eye.

The Combination of Ranibizumab and Laser (CoRaLa) study was a prospective, randomized, interventional Phase IIb clinical trial of 22 patients with non-ischemic CRVO [55]. In this 6-month study, patients were randomized to receive intravitreal ranibizumab versus ranibizumab plus selective laser photocoagulation to areas of peripheral non-perfusion. The study showed that patients receiving combination therapy had better gains in BCVA (5 ETDRS letters vs. 0 ), and a smaller increase in areas of retinal non-perfusion compared to the monotherapy group.

Other studies have similarly reported improvements in BCVA $[55,56]$, reduction in macular edema $[56,57]$ and reduction in the number of anti-VEGF injections required [56] following the application of TRP.

In contrast, the Role of Laser in the Management of Retinal Vein Occlusion (RELATE) study reported no significant difference in BCVA between the group treated with monotherapy and combination therapy [58]. In the Wide-field Angiography Guided Targeted Retinal Photocoagulation Combined with Anti-VEGF Intravitreal Injections for the Treatment of Ischemic Retinal Vein Occlusion (WAVE) study [59], the proportion of patients gaining $\geq 15$ letters was similar in both groups $(33 \%$ vs. $38 \%$ ), and the reduction in central retinal thickness was also similar $(-186$ um vs. -188 um $(\mathrm{p}=0.99)$. Both groups also had similar number of injections (mean 9.5 vs. 8.8).

\section{Conclusion}

UWF imaging plays an important role in the assessment and management of various retinal conditions. In RVO, UWF FA is essential for measuring areas of retinal non-perfusion, especially in the periphery. The extent of retinal non-perfusion may correlate with disease severity and treatment response.

\begin{abstract}
Abbreviations
RVO: retinal vein occlusion; CRVO: central retinal vein occlusion; BRVO: branch retinal vein occlusion; VA: visual acuity; VEGF: vascular endothelial growth factor; PEDF: pigment epithelium-derived factor; ETDRS: Early Treatment Diabetic Retinopathy Study; 7SF: 7 standard field; UWF: ultra-widefield; CVOS: Central Vein Occlusion Study; RAVE: Rubeosis anti-VEGF; FA: fluorescein angiography; OCT: optical coherence tomography; WAVE: Wide-field Angiography Guided Targeted Retinal Photocoagulation Combined with Anti-VEGF Intravitreal Injections for the Treatment of Ischemic Retinal Vein Occlusion; PMA: perimacular area; NPA: near-peripheral area; MPA: mid-peripheral area; FPA: farperipheral area; TRP: targeted retinal photocoagulation; CoRaLa: Combination of Ranibizumab and Laser; RELATE: Role of Laser in the Management of Retinal Vein Occlusion.
\end{abstract}

\section{Authors' contributions}

KZL and CST performed the literature review and analyzed the current relevant literature. CST and SRS were major contributors in writing the manuscript. All authors read and approved the final manuscript.

\section{Author details}

${ }^{1}$ National Healthcare Group Eye Institute, Tan Tock Seng Hospital, Jalan Tan Tock Seng, 11, Singapore 308433, Singapore. ${ }^{2}$ Fundus Image Reading Center, National Healthcare Group Eye Institute, Singapore, Singapore. ${ }^{3}$ Duke-NUS Medical School, Singapore, Singapore. ${ }^{4}$ Lee Kong Chian School of Medicine, Nanyang Technological University, Singapore, Singapore. ${ }^{5}$ Doheny Eye Institute, University of California, Los Angeles, CA, USA.

\section{Acknowledgements}

Not applicable. 


\section{Competing interests}

CST-Research Support from National Medical Research Council Transition Award (NMRC/TA/0039/2015). Conference support from Bayer, Heidelberg Engineering and Novartis. KZL_none. SRS—Consultant for Allegan, Genentech, Roche, Novartis, Iconic, Thrombogenics, Centervue, Heidelberg, Optos and Carl Zeiss Meditec. Research Support from Allergan, Genentech, Optos, and Carl Zeiss Meditec.

\section{Availability of data and materials}

Not applicable.

\section{About this supplement}

This article has been published as part of International Journal of Retina and Vitreous, Volume 5 Supplement 1, 2019: Wide-field imaging in retina and vitreous diseases. The full contents of the supplement are available at https://journ alretinavitreous.biomedcentral.com/articles/supplements/volume-5-suppl ement-1.

\section{Consent for publication}

Not applicable.

\section{Ethics approval and consent to participate}

Not applicable.

\section{Funding}

The publication costs for this paper in the supplement were made possible with unconditional financial support from Optos. The sponsor had no input into the content of articles, which were independently prepared by the authors and have undergone the journal's standard peer-review process.

\section{Publisher's Note}

Springer Nature remains neutral with regard to jurisdictional claims in published maps and institutional affiliations.

\section{Received: 6 February 2019 Accepted: 9 April 2019}

Published: 12 December 2019

\section{References}

1. Jaulim A, Ahmed B, Khanam T, Chatziralli IP. Branch retinal vein occlusion: epidemiology, pathogenesis, risk factors, clinical features, diagnosis, and complications. An update of the literature. Retina. 2013:33:901-10.

2. Rogers SL, Mclntosh RL, Lim L, Mitchell P, Cheung N, Kowalski JW, Nguyen HP, Wang JJ, Wong TY. Natural history of branch retinal vein occlusion: an evidence-based systematic review. Ophthalmology. 2010;117(1094-1101):e1095

3. Klein R, Klein BE, Moss SE, Meuer SM. The epidemiology of retinal vein occlusion: the Beaver Dam Eye Study. Trans Am Ophthalmol Soc. 2000;98:133-41 (discussion 141-133)

4. Cheung N, Klein R, Wang JJ, Cotch MF, Islam AF, Klein BE, Cushman M, Wong TY. Traditional and novel cardiovascular risk factors for retinal vein occlusion: the multiethnic study of atherosclerosis. Invest Ophthalmol Vis Sci. 2008:49:4297-302.

5. Hayreh SS, Zimmerman B, McCarthy MJ, Podhajsky P. Systemic diseases associated with various types of retinal vein occlusion. Am J Ophthalmol. 2001;131:61-77.

6. Mitchell P, Smith W, Chang A. Prevalence and associations of retinal vein occlusion in Australia. The Blue Mountains Eye Study. Arch Ophthalmol. 1996;114:1243-7.

7. Ho M, Liu DT, Lam DS, Jonas JB. Retinal vein occlusions, from basics to the latest treatment. Retina. 2016;36:432-48.

8. The Central Vein Occlusion Study Group. Natural history and clinical management of central retinal vein occlusion. Arch Ophthalmol. 1997;115:486-91.

9. Mitry D, Bunce C, Charteris D. Anti-vascular endothelial growth factor for macular oedema secondary to branch retinal vein occlusion. Cochrane Database Syst Rev. 2013;1:Cd009510.
10. Ehlers JP, Kim SJ, Yeh S, Thorne JE, Mruthyunjaya P, Schoenberger SD, Bakri SJ. Therapies for macular edema associated with branch retinal vein occlusion: a report by the American Academy of Ophthalmology. Ophthalmology. 2017;124:1412-23.

11. Koss MJ, Pfister M, Rothweiler F, Michaelis M, Cinatl J, Schubert R, Koch $\mathrm{FH}$. Comparison of cytokine levels from undiluted vitreous of untreated patients with retinal vein occlusion. Acta Ophthalmol. 2012:90:e98-103.

12. Noma H, Funatsu H, Mimura T, Harino S, Hori S. Vitreous levels of interleukin-6 and vascular endothelial growth factor in macular edema with central retinal vein occlusion. Ophthalmology. 2009;116:87-93.

13. Noma H, Funatsu H, Mimura T, Eguchi S, Shimada K, Hori S. Vitreous levels of pigment epithelium-derived factor and vascular endothelial growth factor in macular edema with central retinal vein occlusion. Curr Eye Res. 2011:36:256-63.

14. McIntosh RL, Rogers SL, Lim L, Cheung N, Wang JJ, Mitchell P, Kowalski JW, Nguyen HP, Wong TY. Natural history of central retinal vein occlusion: an evidence-based systematic review. Ophthalmology. 2010:117(1113-1123):e1115.

15. Tan CS, Hariprasad SM, Lim LW, Sadda SR. Evaluation of the retinal and choroidal vasculature with OCT angiography versus conventional angiography. Ophthalmic Surg Lasers Imaging Retina. 2016;47:1081-5.

16. Tan CS, Cheong KX. Macular choroidal thicknesses in healthy adultsrelationship with ocular and demographic factors. Invest Ophthalmol Vis Sci. 2014;55:6452-8.

17. Tan CS, Cheong KX, Lim LW, Li KZ. Topographic variation of choroidal and retinal thicknesses at the macula in healthy adults. Br J Ophthalmol. 2014:98:339-44.

18. Tan CS, Ngo WK, Cheong KX. Comparison of choroidal thicknesses using swept source and spectral domain optical coherence tomography in diseased and normal eyes. Br J Ophthalmol. 2015;99:354-8.

19. Tan CS, Cheong KX, Lim LW, Sadda SR. Comparison of macular choroidal thicknesses from swept source and spectral domain optical coherence tomography. Br J Ophthalmol. 2016:100:995-9.

20. Adhi M, Silva FQ, Lang R, Seballos R, Sukol RB, Feinleib S, Singh RP. Nonmydriatic ultra-widefield imaging compared with single-field imaging in the evaluation of peripheral retinal pathology. Ophthalmic Surg Lasers Imaging Retina. 2017;48:962-8.

21. Thomas AS, Redd T, Campbell JP, Palejwala NV, Baynham JT, Suhler EB, Rosenbaum JT, Lin P. The impact and implication of peripheral vascular leakage on ultra-widefield fluorescein angiography in uveitis. Ocul Immunol Inflamm 2017;16:1-7.

22. Rabiolo A, Marchese A, Sacconi R, Cicinelli MV, Grosso A, Querques L, Querques G, Bandello F. Refining Coats' disease by ultra-widefield imaging and optical coherence tomography angiography. Graefes Arch Clin Exp Ophthalmol. 2017;255:1881-90.

23. Early Treatment Diabetic Retinopathy Study Research Group. Early photocoagulation for diabetic retinopathy. ETDRS report number 9. Ophthalmology. 1991;98:766-85.

24. Diabetic Retinopathy. Diabetic retinopathy study. Report Number 6 . Design, methods, and baseline results. Report Number 7. A modification of the Airlie House classification of diabetic retinopathy. Invest Ophthalmol Vis Sci. 1981;21:1-226.

25. Silva PS, Cavallerano JD, Sun JK, Soliman AZ, Aiello LM, Aiello LP. Peripheral lesions identified by mydriatic ultrawide field imaging: distribution and potential impact on diabetic retinopathy severity. Ophthalmology. 2013;120:2587-95

26. Tan CS, Sadda SR, Hariprasad SM. Ultra-widefield retinal imaging in the management of diabetic eye diseases. Ophthalmic Surg Lasers Imaging Retina. 2014;45:363-6.

27. Friberg TR, Pandya A, Eller AW. Non-mydriatic panoramic fundus imaging using a non-contact scanning laser-based system. Ophthalmic Surg Lasers Imaging. 2003;34:488-97.

28. Nagiel A, Lalane RA, Sadda SR, Schwartz SD. Ultra-widefield fundus imaging: a review of clinical applications and future trends. Retina. 2016:36:660-78.

29. Silva PS, Cavallerano JD, Sun JK, Noble J, Aiello LM, Aiello LP. Nonmydriatic ultrawide field retinal imaging compared with dilated standard 7-field 35-mm photography and retinal specialist examination for evaluation of diabetic retinopathy. Am J Ophthalmol. 2012;154(549-559):e542.

30. Tan CS, Heussen F, Sadda SR. Peripheral autofluorescence and clinical findings in neovascular and non-neovascular age-related macular degeneration. Ophthalmology. 2013;120:1271-7. 
31. Heussen FM, Tan CS, Sadda SR. Prevalence of peripheral abnormalities on ultra-widefield greenlight (532 nm) autofluorescence imaging at a tertiary care center. Invest Ophthalmol Vis Sci. 2012;53:6526-31.

32. Klufas MA, Tsui I, Sadda SR, Hosseini H, Schwartz SD. Ultrawidefield autofluoresence in Abca4 Stargardt disease. Retina. 2018;38:403-15.

33. Tan CS, Chew MC, van Hemert J, Singer MA, Bell D, Sadda SR. Measuring the precise area of peripheral retinal non-perfusion using ultra-widefield imaging and its correlation with the ischaemic index. Br J Ophthalmol. 2016:100:235-9.

34. Seo EJ, Kim JG. Analysis of the normal peripheral retinal vascular pattern and its correlation with microvascular abnormalities using ultra-widefield fluorescein angiography. Retina. 2017;39:530-6.

35. Laovirojjanakul W, Acharya N, Gonzales JA. Ultra-widefield fluorescein angiography in intermediate uveitis. Ocul Immunol Inflamm 2017;17:1-6.

36. Klufas MA, Yannuzzi NA, Pang CE, Srinivas S, Sadda SR, Freund KB, Kiss S. Feasibility and clinical utility of ultra-widefield indocyanine green angiography. Retina. 2015;35:508-20.

37. Tan CS, Chew MC, Lim LW, Sadda SR. Advances in retinal imaging for diabetic retinopathy and diabetic macular edema. Indian J Ophthalmol. 2016;64:76-83

38. Seidensticker F, Neubauer AS, Wasfy T, Stumpf C, Thurau SR, Kampik A, Kernt M. Wide-field fundus autofluorescence corresponds to visual fields in chorioretinitis patients. Clin Ophthalmol. 2011;5:1667-71.

39. Singer M, Tan CS, Bell D, Sadda SR. Area of peripheral retinal nonperfusion and treatment response in branch and central retinal vein occlusion. Retina. 2014;34:1736-42.

40. Kiss S, Berenberg TL. Ultra widefield fundus imaging for diabetic retinopathy. Curr Diab Rep. 2014;14:514.

41. Sim DA, Keane PA, Rajendram R, Karampelas M, Selvam S, Powner MB, Fruttiger M, Tufail A, Egan CA. Patterns of peripheral retinal and central macula ischemia in diabetic retinopathy as evaluated by ultra-widefield fluorescein angiography. Am J Ophthalmol. 2014;158(144-153):e141.

42. Virdi PS, Hayreh SS. Ocular neovascularization with retinal vascular occlusion. I. Association with experimental retinal vein occlusion. Arch Ophthalmol. 1982:100:331-41.

43. Hayreh SS, Zimmerman MB. Ocular neovascularization associated with central and hemicentral retinal vein occlusion. Retina. 2012;32:1553-65.

44. DICOM Standards Committee. Supplement 173: wide field ophthalmic photography image storage SOP classes (DICOM Standards Committee), DICOM Work Item 2013-12-A undertaken by WG 9 (Ophthalmology), 2015.

45. Tsui I, Kaines A, Havunjian MA, Hubschman S, Heilweil G, Prasad PS, Oliver SC, Yu F, Bitrian E, Hubschman JP, et al. Ischemic index and neovascularization in central retinal vein occlusion. Retina. 2011;31:105-10.

46. Croft DE, van Hemert J, Wykoff CC, Clifton D, Verhoek M, Fleming A, Brown DM. Precise montaging and metric quantification of retinal surface area from ultra-widefield fundus photography and fluorescein angiography. Ophthalmic Surg Lasers Imaging Retina. 2014;45:312-7.
47. Sagong M, van Hemert J, Olmos de Koo LC, Barnett C, Sadda SR. Assessment of accuracy and precision of quantification of ultra-widefield images. Ophthalmology. 2015;122:864-6.

48. Spaide RF. Peripheral areas of nonperfusion in treated central retinal vein occlusion as imaged by wide-field fluorescein angiography. Retina. 2011;31:829-37.

49. Singer $M$, Sagong $M$, van Hemert J, Kuehlewein L, Bell D, Sadda SR. Ultra-widefield Imaging of the peripheral retinal vasculature in normal subjects. Ophthalmology. 2016;123:1053-9.

50. Wykoff CC, Brown DM, Croft DE, Major JC Jr, Wong TP. Progressive retinal nonperfusion in ischemic central retinal vein occlusion. Retina. 2015;35:43-7.

51. Prasad PS, Oliver SC, Coffee RE, Hubschman JP, Schwartz SD. Ultra widefield angiographic characteristics of branch retinal and hemicentral retinal vein occlusion. Ophthalmology. 2010;117:780-4

52. Abri Aghdam K, Reznicek L, Soltan Sanjari M, Framme C, Bajor A, Klingenstein A, Kernt M, Seidensticker F. Peripheral retinal non-perfusion and treatment response in branch retinal vein occlusion. Int J Ophthalmol. 2016;9:858-62

53. Kwon S, Wykoff CC, Brown DM, van Hemert J, Fan W, Sadda SR. Changes in retinal ischaemic index correlate with recalcitrant macular oedema in retinal vein occlusion: WAVE study. Br J Ophthalmol. 2018;102:1066-71.

54. Abri Aghdam K, Reznicek L, Soltan Sanjari M, Klingenstein A, Kernt M, Seidensticker F. Anti-VEGF treatment and peripheral retinal nonperfusion in patients with central retinal vein occlusion. Clin Ophthalmol. 2017;11:331-6.

55. Rehak M, Tilgner E, Franke A, Rauscher FG, Brosteanu O, Wiedemann P. Early peripheral laser photocoagulation of nonperfused retina improves vision in patients with central retinal vein occlusion (results of a proof of concept study). Graefes Arch Clin Exp Ophthalmol. 2014;252:745-52.

56. Tomomatsu Y, Tomomatsu T, Takamura Y, Gozawa M, Arimura S, Takihara Y, Inatani M. Comparative study of combined bevacizumab/targeted photocoagulation vs bevacizumab alone for macular oedema in ischaemic branch retinal vein occlusions. Acta Ophthalmol. 2016;94:e225-30.

57. Singer MA, Tan CS, Surapaneni KR, Sadda SR. Targeted photocoagulation of peripheral ischemia to treat rebound edema. Clin Ophthalmol. 2015;9:337-41

58. Campochiaro PA, Hafiz G, Mir TA, Scott AW, Solomon S, Zimmer-Galler I, Sodhi A, Duh E, Ying H, Wenick A, et al. Scatter photocoagulation does not reduce macular edema or treatment burden in patients with retinal vein occlusion: the RELATE trial. Ophthalmology. 2015;122:1426-37.

59. Wykoff CC, Ou WC, Wang R, Brown DM, Cone C, Zamora D, Le RT, Sagong M, Wang K, Sadda SR. Peripheral laser for recalcitrant macular edema owing to retinal vein occlusion: the WAVE trial. Ophthalmology. 2017;124:919-21.

Ready to submit your research? Choose BMC and benefit from

- fast, convenient online submission

- thorough peer review by experienced researchers in your field

- rapid publication on acceptance

- support for research data, including large and complex data types

- gold Open Access which fosters wider collaboration and increased citations

- maximum visibility for your research: over 100M website views per year

At $\mathrm{BMC}$, research is always in progress.

Learn more biomedcentral.com/submissions 